\title{
Inhibition of neutrophil elastase-induced goblet cell metaplasia by tiotropium in mice
}

\author{
N. Arai, M. Kondo, T. Izumo, J. Tamaoki and A. Nagai
}

ABSTRACT: Airway occlusion by mucus in chronic obstructive disease (COPD) is associated with a poor prognosis. We hypothesised that tiotropium has the ability to inhibit neutrophil elastase (NE)-induced goblet cell metaplasia in mice and mucin production in vitro.

On days 1, 4, and 7, tiotropium or vehicle was administered to $\mathrm{C} 57 \mathrm{BL} / 6$ mice by inhalation and they were allowed to intranasally aspirate human NE. Bronchoalveolar lavage fluid (BALF) and lung sections were analysed on days 8, 11 and 14. The effect of late administration of tiotropium on the goblet cell metaplasia by NE aspiration was also assessed. NE-induced MUC5AC production by $\mathrm{NCl}-\mathrm{H} 292$ cells was measured with ELISA.

Repeated NE aspiration induced marked goblet cell metaplasia. The grading of goblet cell metaplasia, neutrophil count and eosinophil count in BALF, keratinocyte-derived chemokine level and leukotriene $B_{4}$ level in $B A L F$, and $M_{3}$ receptor expression by immunohistochemistry, were lower in the tiotropium group than in the vehicle group. Late administration of tiotropium inhibited the established goblet cell metaplasia. Tiotropium inhibited NE-induced MUC5AC production.

Tiotropium inhibited NE-induced goblet cell metaplasia and mucin production, probably mediated by suppression of inflammation and a direct action on epithelial cells. This result suggests that tiotropium may be useful for the treatment of mucus overproduction in COPD.

KEYWORDS: Goblet cell metaplasia, inflammation, mucin, neutrophil elastase, tiotropium

M ucus overproduction due to goblet cell metaplasia is one of the characteristic features of chronic obstructive pulmonary disease (COPD). It has recently been reported that occlusion of bronchial lumens by mucuscontaining inflammatory exudates is negatively correlated with forced expiratory volume in $1 \mathrm{~s}$ (FEV1) over the full range of COPD severity [1]. Reduction of FEV1 leads to more frequent exacerbations of COPD. Impaired mucus clearance is associated with pneumonia that results in early death in patients with severe COPD [2]. Thus, mucus control may serve as a therapeutic target for improving the prognosis of COPD.

Neutrophil elastase (NE) is a serine protease that stimulates mucus secretion [3], and its level is increased in the sputum with nanomolar or micromolar concentrations in chronic bronchitis [4]. NE is generally used for an animal model of emphysema, based on the hypothesis that COPD is caused by an imbalance between protease activity and antiprotease activity. Although the studies were focused on assessing the destruction of alveoli and small airways, goblet cell metaplasia has not fully been studied in this model.

The long-acting cholinergic antagonist, tiotropium, is widely used as a bronchodilator in the treatment of COPD. Because tiotropium improves FEV1 and the St George's Respiratory Questionnaire score, it increases the time to the first exacerbations and reduces the number of exacerbation of COPD $[5,6]$. There is accumulating evidence that the cholinergic system controls not only contraction by airway smooth muscle but also the functions of inflammatory cells and airway epithelial cells [7]. Recent evidence suggests that tiotropium has anti-inflammatory effect in COPD. In this study, we investigated whether tiotropium has the ability to inhibit goblet cell metaplasia in a NE-induced murine model of COPD. In addition, we investigated whether tiotropium directly inhibits NE-induced mucin production in NCI-H292, a well-established cell line to study mucin production [8].

\section{MATERIALS AND METHODS}

In vivo study using an NE-induced murine model of COPD

The animal protocol was approved by the Animal Care and Use Committee of Tokyo Women's Medical University. We used 6-week-old C57BL/ 6 male mice and divided them into two groups. The first protocol (protocol A) is shown as figure 1a. On days 1, 4 and 7, tiotropium or vehicle was administered by inhalation to the groups for $30 \mathrm{~min}$ by placing five to 10 mice per
AFFILIATIONS

First Dept of Medicine, Tokyo Women's Medical University School of Medicine, Tokyo, Japan.

CORRESPONDENCE

A. Nagai

First Dept of Medicine

Tokyo Women's Medical University School of Medicine

8-1 Kawada-cho

Shinjuku-ku

Tokyo 162-8666

Japan

E-mail: anagai@chi.twmu.ac.jp

Received:

March 122009

Accepted after revision:

Oct 192009

First published online:

Nov 062009 
group in an acrylic box $(14.5 \times 21.0 \times 14.5 \mathrm{~cm})$ under conscious and unrestrained conditions and exposing them to aerosols of tiotropium diluted in sterile saline $\left(10^{-5} \mathrm{M}\right.$; Boehringer Ingelheim Co., Ingelheim am Rhein, Germany) or vehicle (sterile saline) with an ultrasonic nebuliser (Pulmo-Sonic model 25; DeVilbiss Co. Somerset, PA, USA). The aerosols were allowed to escape through two exhaust holes $(1 \mathrm{~cm})$ on the side panels of the box to ensure constant airflow. 30 min after the completion of the inhalation, both groups were allowed to intranasally aspirate human NE $(50 \mu \mathrm{g}$; Elastin Products, Owensville, MO, USA) dissolved in saline $80 \mu \mathrm{L}$ under ether anaesthesia. The group exposed to tiotropium will be referred to as the tiotropium group, and the group exposed to vehicle will be referred to as the NE group. Bronchoalveolar lavage fluid (BALF) and the histology of the lung tissues were analysed on day 8,11 and 14. The NE group and the tiotropium group on each day are referred to as N8, N11, and N14 and as T8, T11, and T14, respectively. Since we confirmed that mice that aspirated saline intranasally on days 1,4 and 7 developed little or no goblet cell metaplasia, the same as reported by Vornow et al. [9], we used mice that had aspirated NE in this study to elucidate the effect of tiotropium. To assess the time course of goblet cell metaplasia, the NE group on day 20 (N20) and nontreated control mice group were analysed for histology of the lung tissues as a separate experiment.

For BALF analysis, mice were anesthetised with pentobarbital (50 $\mathrm{mg} \cdot \mathrm{kg}^{-1}$, intraperitoneally), and, after performing a tracheotomy, a custom-built cannula was inserted into the trachea. The lungs were lavaged with $1.0 \mathrm{~mL}$ of saline or PBS, and then with $0.8 \mathrm{~mL}$ of the same solution. The BALF was centrifuged at $360 \times g$ for $10 \mathrm{~min}$, and the supernatant was collected and stored at $-80^{\circ} \mathrm{C}$ for subsequent measurement of keratinocyte-derived chemokine (KC); the mouse ortholog of human interleukin (IL)-8, IL-5 and leukotriene (LT) $B_{4}$. The total cell number was counted manually with a haemocytometer. Slides of BALF cells were prepared with cytospin and, after staining with May-Grünwald-Giemsa stain, differential counts of $\sim 1000$ cells per sample were made. The KC levels and IL-5 levels in BALF were measured with a mouse $\mathrm{KC}$ and IL-5 ELISA kit (R\&D system, Minneapolis, MN, USA). The $\mathrm{LTB}_{4}$ levels in BALF were measured with an enzyme immunoassay system (Amersham Biosciences, Piscataway, NJ, USA)

For histological analysis of the lungs, the lungs were fixed by inflation with $4 \%$ paraformaldehyde and embedded in paraffin. Sections were cut $5 \mu \mathrm{m}$ thick and stained with periodic acidSchiff/Alcian-blue. The assessments were made at stratified random fields $(n=5)$ in each animal, as described by NAGAI $e t$ al. [10]. Goblet cell metaplasia was assessed in bronchi with internal diameter measuring $>200 \mu \mathrm{m}$ in cross section, using a mucus grading system (scores 0-3), based on the ratio of goblet cell area to whole cross-sectional epithelial area in each round bronchus: a score of 0 means none, a score of 1 indicates occupation of $<1 / 3$ of the epithelial area; a score of 2 indicates occupation of $\geqslant 1 / 3$ $<2 / 3$ of the epithelial area; and a score of 3 indicates occupation of $\geqslant 2 / 3$ of the epithelial area. The mucus score was obtained by averaging the scores of measured bronchi.

For immunohistochemistry, after deparaffinising sections in xylene and dehydrating them in ethanol, they were treated

with peroxidase-blocking solution (DakoCytomation; A/S, Glostrup, Denmark) for $10 \mathrm{~min}$ at room temperature to block endogenous peroxidase activity. Next, they were treated with Protein Block Serum-Free (DakoCytomation) for $10 \mathrm{~min}$ at room temperature. The sections were then incubated with goat polyclonal anti-M 3 antibody (1:100 C-20; Santa Cruz Biotechnology, Inc., Santa Cruz, CA, USA) at room temperature for $1 \mathrm{~h}$. The primary antibodies were then treated with the labelled polymer prepared by combining amino acid polymers with peroxidase and secondary antibody ( $N$-Histofine Simple Stain Mouse MAX PO; Nichirei Bioscience, Tokyo, Japan). Immunoreactants were visualised with 3,3'-diaminobenzidine and counterstained with nuclear fast red solution. For negative controls, tissue sections were incubated without the addition of primary antibody.

In the second protocol (protocol B, fig. 1b), which was designed to assess the therapeutic effect of late administration of tiotropium on established goblet cell metaplasia in the NEinduced COPD model, the mice were allowed to intranasally aspirate NE six times, i.e. on days 1, 4, 7, 10, 13 and 16. Late tiotropium or vehicle treatment was administered on days 10 13 , and 16 , by allowing animals to inhale tiotropium $\left(10^{-5} \mathrm{M}\right)$ for $30 \mathrm{~min}$ before NE aspiration on these days. On day 20 , BALF was analysed and the goblet cell metaplasia of the lung

a)

NE group

Tiotropium group

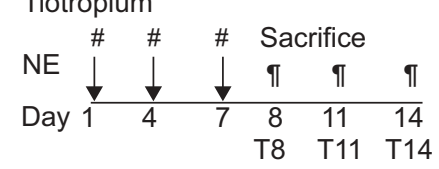

b)

NE group

Tiotropium group

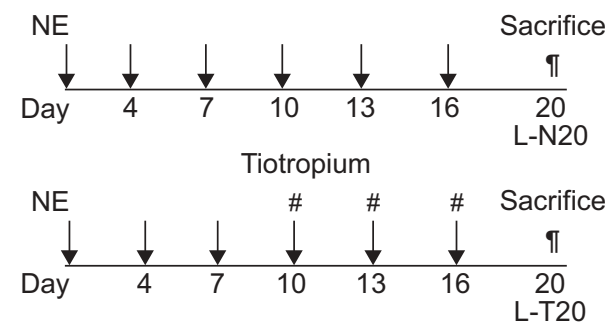

FIGURE 1. Experimental protocols. a) Protocol A: on days 1,4 and 7, C57BL/6 mice inhaled tiotropium $\left(10^{-5} \mathrm{M} ; \#\right)$ (tiotropium group) or vehicle (neutrophil elastase (NE) group) for $30 \mathrm{~min}$, and they aspirated human NE (50 $\mu \mathrm{g}$; arrows) under ether anaesthesia intranasally. The mice were sacrificed ( $\boldsymbol{(}$ ) on days 8,11 and 14, and bronchoalveolar lavage fluid (BALF) and the lung sections were examined. The NE group on days 8,11 and 14 and the tiotropium group on days 8 11 and 14 are referred to as N8, N11, and N14 and as T8, T11, and T14 respectively. b) Protocol B: effect of late administration of tiotropium on established NE-induced goblet cell metaplasia. Mice aspirated NE (arrows) alone intranasally on days 1, 4, and 7. On days 10,13 and 16, mice inhaled tiotropium (tiotropium group; \#) or vehicle (NE group) and then aspirated NE. The mice were sacrificed ( $\uparrow$ ) on day 20, and BALF and the lung sections were examined. The NE group on day 20 and the tiotropium group on day 20 are referred to as L-N20 and L-T2O, respectively. 

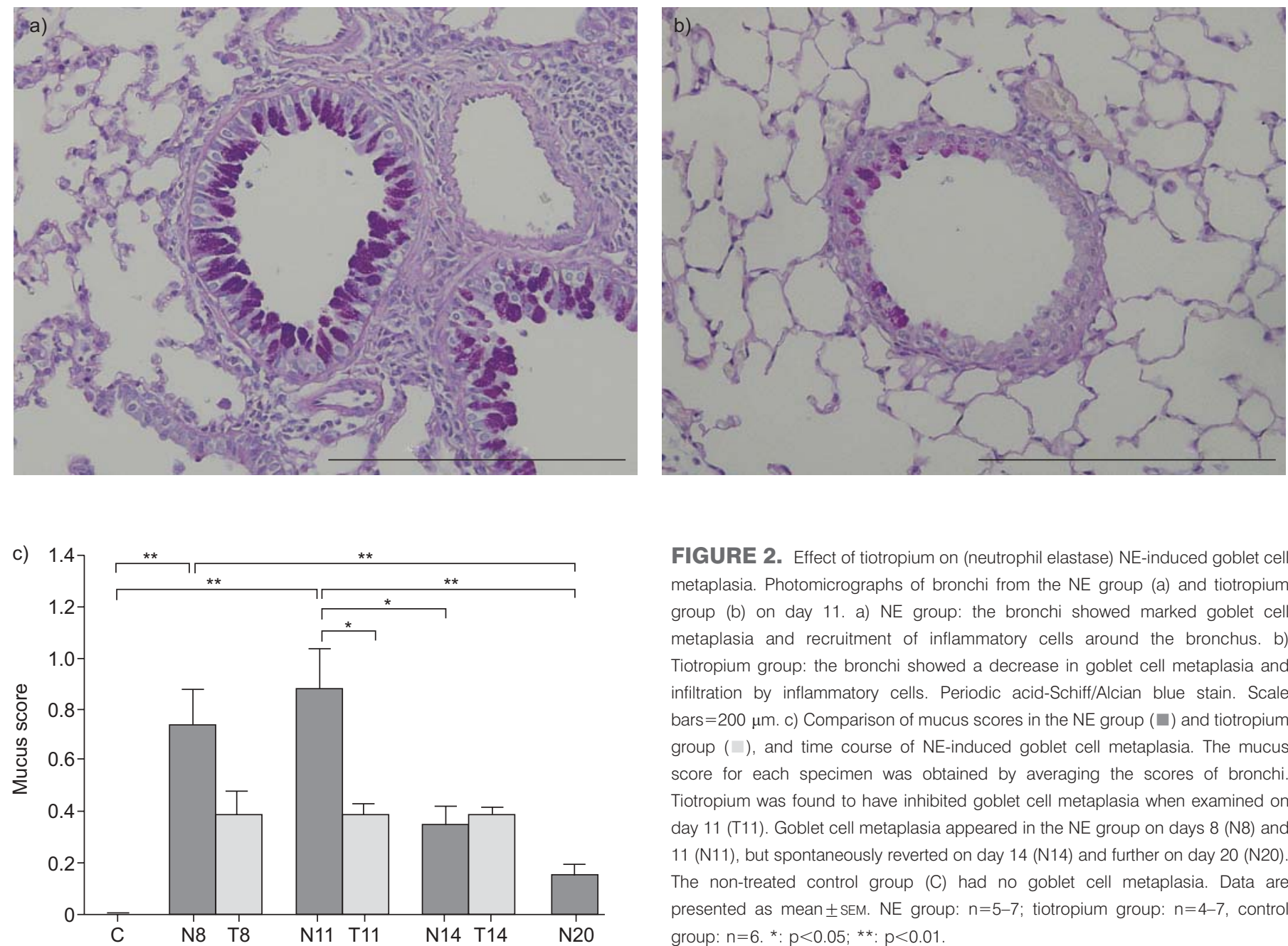

FIGURE 2. Effect of tiotropium on (neutrophil elastase) NE-induced goblet cell metaplasia. Photomicrographs of bronchi from the NE group (a) and tiotropium group (b) on day 11. a) NE group: the bronchi showed marked goblet cell metaplasia and recruitment of inflammatory cells around the bronchus. b) Tiotropium group: the bronchi showed a decrease in goblet cell metaplasia and infiltration by inflammatory cells. Periodic acid-Schiff/Alcian blue stain. Scale bars $=200 \mu \mathrm{m}$. c) Comparison of mucus scores in the NE group ( $\square$ ) and tiotropium group ( $\square$ ), and time course of NE-induced goblet cell metaplasia. The mucus score for each specimen was obtained by averaging the scores of bronchi. Tiotropium was found to have inhibited goblet cell metaplasia when examined on day 11 (T11). Goblet cell metaplasia appeared in the NE group on days 8 (N8) and 11 (N11), but spontaneously reverted on day 14 (N14) and further on day 20 (N20) The non-treated control group (C) had no goblet cell metaplasia. Data are presented as mean \pm SEM. NE group: $n=5-7$; tiotropium group: $n=4-7$, control group: $n=6 .{ }^{*}: p<0.05 ;{ }^{*}: p<0.01$.

tissue was assessed by the same methods as previously described. The NE group and the tiotropium group on day 20 in the late-administration experiment are referred to as LN20 and L-T20, respectively.

\section{In vitro study using $\mathrm{NCl}-\mathrm{H} 292$ cells}

\section{Cell culture}

The human pulmonary mucoepidermoid carcinoma cell line NCI-H292 was grown at $37^{\circ} \mathrm{C}$ in RPMI 1640 medium (GIBCO; Invitrogen Co. Grand Island, NY, USA) with 10\% fetal calf serum, penicillin $\left(100 \mathrm{U} \cdot \mathrm{mL}^{-1}\right)$, streptomycin $\left(100 \mu \mathrm{g} \cdot \mathrm{mL}^{-1}\right)$, and fungizone $\left(2.5 \mu \mathrm{g} \cdot \mathrm{mL}^{-1}\right)$ in a humidified $5 \% \mathrm{CO}_{2}$ waterjacketed incubator. NCI-H292 cells were plated in 6-well culture dishes at an initial density of $1 \times 10^{5} \cdot$ well $^{-1}$ and reached confluence 5 days after plating. The cells were used for in vitro experiment 2 days after confluence. The cell density of the cells was $\sim 4.5 \times 10^{5} \cdot \mathrm{cm}^{-2}$.

\section{Measurement of MUC5AC production}

NCI-H292 cells were serum starved for $24 \mathrm{~h}$ by culturing in the same medium without serum. The serum-starved cells were pre-treated with tiotropium $\left(10^{-6}-10^{-5} \mathrm{M}\right)$ or saline for $30 \mathrm{~min}$ and then replacing the medium with serum-free medium and stimulating them with $\mathrm{NE}\left(10^{-7} \mathrm{M}\right)$ for $10 \mathrm{~min}$ [11]. Then, the

cells were washed and cultured in serum-free medium for an additional $24 \mathrm{~h}$. Mucin-5AC (MUC5AC) protein levels in cell lysates were measured by ELISA (Mucin 5AC mouse monoclonal IgG, Santa Cruz Biotechnology Inc., CA, USA) as previously described by TAKEYAMA et al. [12]. The data are shown as percentage increase over the level in nonstimulated control cells on the same experimental day, but not shown by using a mucin standard curve to calculate MUC5AC protein $[13,14]$. In additional experiments, we examined whether ipratropium inhibits NE-induced MUC5AC production, and whether carbachol affects MUC5AC production to confirm the role of muscarinic receptors in NCI-H292 cells. For ipratropium experiment, the cells were pre-treated with ipratropium $\left(10^{-5} \mathrm{M}\right.$, Sigma-Aldrich, St Louis, MO, USA) for $30 \mathrm{~min}$, and stimulated with $\mathrm{NE}\left(10^{-7} \mathrm{M}\right)$ for $10 \mathrm{~min}$. For carbachol experiment, the cells were pre-treated with tiotropium $\left(10^{-5} \mathrm{M}\right)$ or saline for $30 \mathrm{~min}$, and stimulated with carbachol $\left(10^{-6} \mathrm{M}\right.$, Sigma-Aldrich) for $10 \mathrm{~min}$.

\section{STATISTICS}

Data are expressed as mean \pm SEM. Multiple comparisons were performed by using the Tukey-Kramer test. Comparisons between two groups were performed by using a two-tailed unpaired t-test. A p-value $<0.05$ was considered significant. 

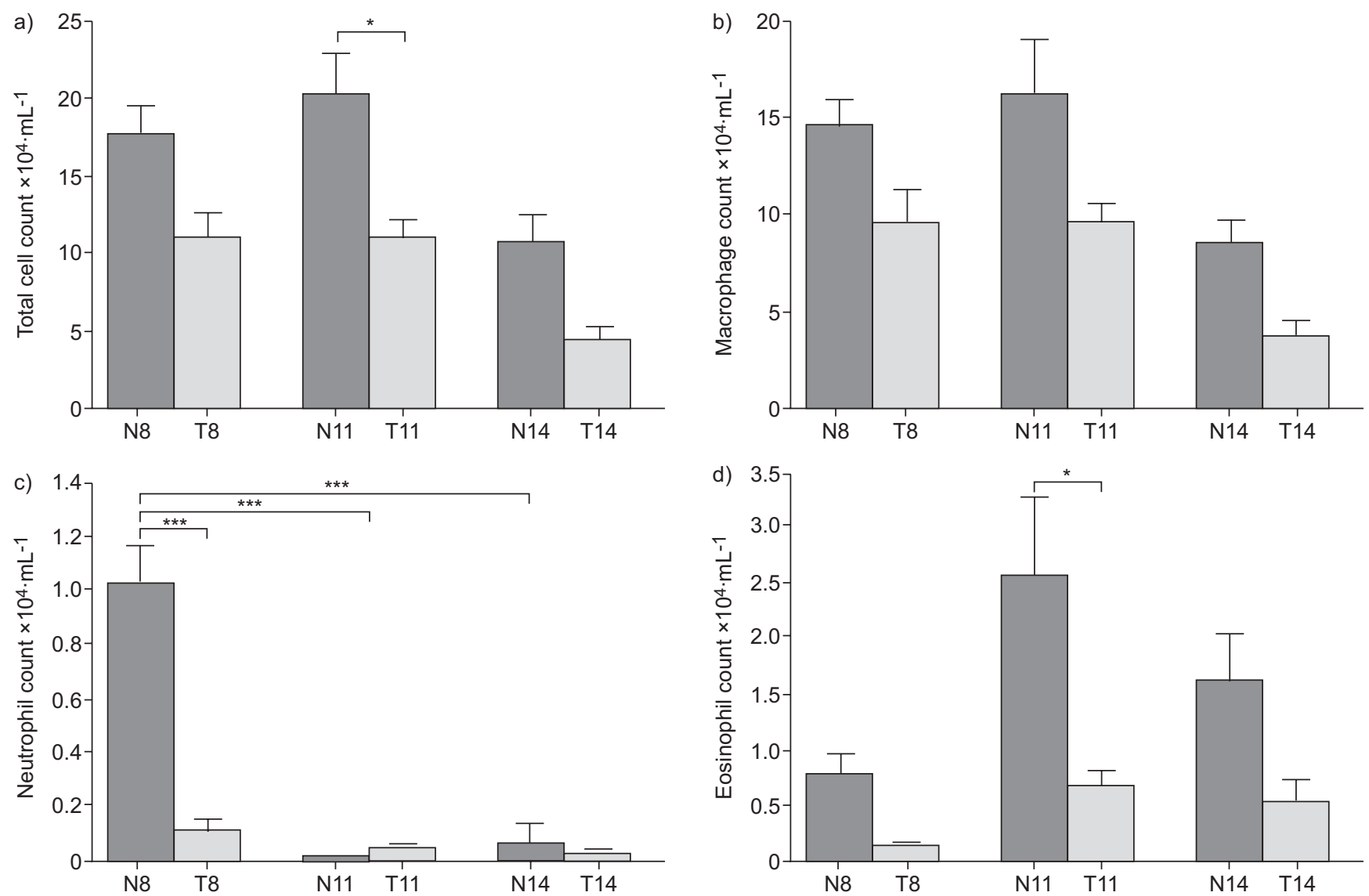

FIGURE 3. Comparison between the results of the bronchoalveolar lavage fluid cell analysis in the neutrophil elastase group ( $\square$ ) and tiotropium group ( $\square$ ). a) Total cell count, b) macrophage count, c) neutrophil count and d) eosinophil count. Tiotropium inhibited the increase in the total cell count and eosinophil count on day 11 (T11) and the increase in neutrophil count on day 8 (T8). Data are presented as mean \pm SEM. $n=5-9$. *: $p<0.05$; ${ }^{* *}: p<0.001$.

\section{RESULTS}

\section{In vivo study}

\section{Goblet cell metaplasia}

As shown in figure $2 \mathrm{a}$ and $\mathrm{b}, \mathrm{NE}$ aspiration, in triplicate, had induced goblet cell metaplasia with inflammatory cell infiltration when C57BL/ 6 mice were examined on day 11, whereas tiotropium pre-treatment strongly inhibited the development of goblet cell metaplasia. The mucus score as a measure of NEinduced goblet cell metaplasia was significantly lower in T11 than in N11 (N11 versus T11: $0.871 \pm 0.170$ versus $0.365 \pm 0.064$; $\mathrm{n}=6$ and $\mathrm{n}=7$, respectively; $\mathrm{p}<0.05$; fig. $2 \mathrm{c}$ ). The mucus score in T8 also tended to be lower than that in N8; however, the mucus score in T14 was not different from that in N14. Since the mucus score in N14 was significantly lower than that in N11 (N11 versus N14: $0.871 \pm 0.170$ versus. $0.342 \pm 0.080 ; n=6$ and $n=5$, respectively; $p<0.05$; fig. $2 \mathrm{c}$ ), these data indicated that NE-induced goblet cell metaplasia spontaneously reverted at 7 days after the last NE exposure. To confirm the reversion, we analysed the mucus scores in N20 and in the non-treated control group as an additional experiment. The mucus score in N20 $(0.146 \pm 0.270 ; n=6)$ was further decreased compared with N14 (fig. 2c); however, a slight goblet cell metaplasia remained in N20, whereas the non-treated control group had no goblet cell metaplasia.

\section{$B A L F$ analysis}

The total cell count in BALF on day 11 was significantly lower in the tiotropium group than in the NE group (N11 versus T11: $19.89 \pm 3.02 \times 10^{4}$ versus $10.97 \pm 1.10 \times 10^{4}$ per $\mathrm{mL} ; \mathrm{p}<0.05 ; \mathrm{n}=8$ and $n=9$, respectively; fig. 3a). Neutrophils were first noted in the NE group on day 8 , and tiotropium inhibited NE-induced neutrophil accumulation on day 8 (N8 versus T8: $1.02 \pm 0.14 \times 10^{4}$ versus $0.10 \pm 0.06 \times 10^{4}$ per $\mathrm{mL} ; \mathrm{p}<0.001 ; \mathrm{n}=9$ and $\mathrm{n}=5$, respectively; fig. 3c). The eosinophil count on day 11 was significantly lower in the tiotropium group than in the NE group (N11 versus $\mathrm{T} 11: 2.55 \pm 0.70 \times 10^{4}$ versus $0.68 \pm 0.13 \times 10^{4}$ per $\mathrm{mL} ; \mathrm{p}<0.05 ; \mathrm{n}=8$ and $n=9$, respectively; fig. $3 d$ ). The macrophage counts tended to be lower in the tiotropium group, but the differences were not significant (fig. 3b). There were not significant differences between the lymphocyte counts in the two groups (data not shown). KC was detected in BALF only on day 8 (fig. 4a). The KC levels were significantly lower in T8 than in N8 (N8 versus T8; $10.58 \pm 0.75$ versus $3.93 \pm 0.81 \mathrm{pg} \cdot \mathrm{mL}^{-1} ; \mathrm{p}<0.001 ; \mathrm{n}=6$ and $\mathrm{n}=7$, respectively). IL-5 was detected in BALF on days 8, 11 and 14 in both groups but there were no significant differences between the groups (fig. 4b). $\mathrm{LTB}_{4}$ was detected on days 8, 11 and 14 in both groups, and the $\mathrm{LTB}_{4}$ level was significantly lower in the tiotropium group on day 11 (N11 versus $\mathrm{T} 11 ; 151.1 \pm 15.7$ versus $109.8 \pm 11.2 \mathrm{pg} \cdot \mathrm{mL}^{-1} ; \mathrm{p}<0.05 ; \mathrm{n}=9$; fig. $\left.4 \mathrm{c}\right)$. 

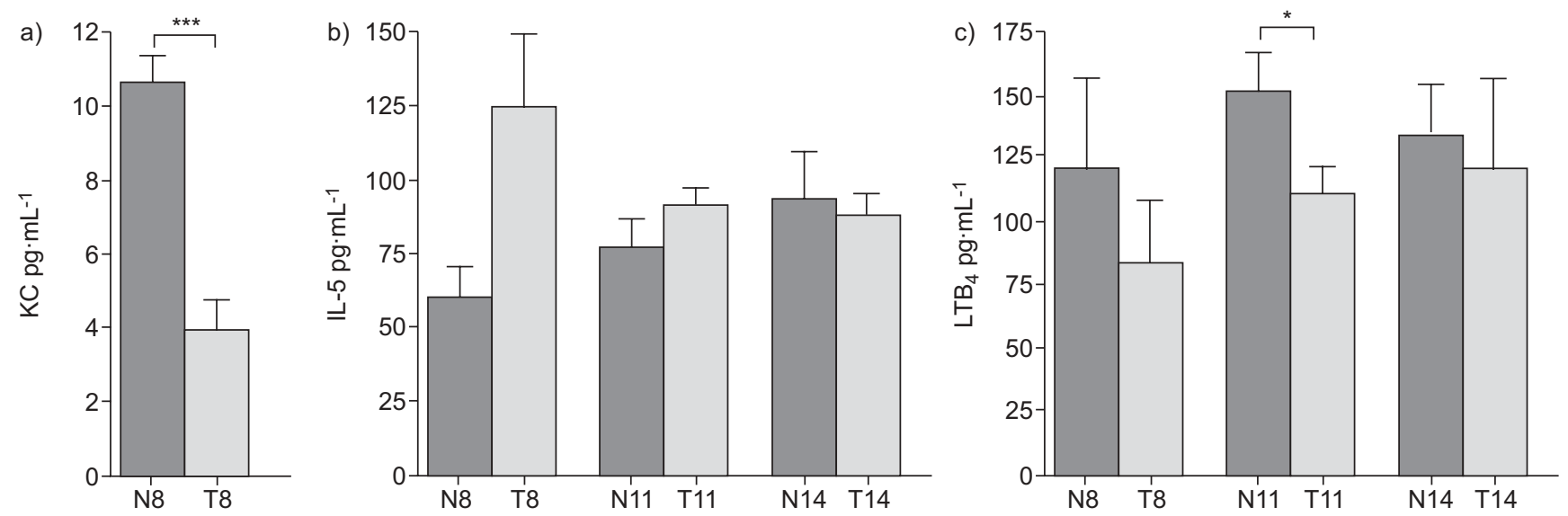

FIGURE 4. The comparison between a) keratinocyte-derived chemokine (KC), b) interleukin (IL)-5, and c) leukotriene (LT) $B_{4}$ levels in the bronchoalveolar lavage fluid of the neutrophil elastase group $(\square)$ and tiotropium group $(\square)$. KC was detected only on day 8 and the level was significantly lower in the tiotropium group. There were no significant differences in IL-5 levels between the two groups. The LTB 4 level was significantly lower in the tiotropium group on day 11 (T11). Data are presented as mean \pm SEM $n=6-9 . *: p<0.05 . * * *: p<0.001$

\section{Immunohistochemistry}

Figure 5 shows $\mathrm{M}_{3}$ receptor expression of the lung sections by immunohistochemistry on day 11 . Strong $\mathrm{M}_{3}$ expression was especially observed in bronchial epithelial cells and inflammatory cells in the NE group (fig. 5a). The $\mathrm{M}_{3}$ receptor expression in the tiotropium group was less than that in the NE group (fig. 5b).

Therapeutic effect of late administration of tiotropium on established goblet cell metaplasia

The results of protocol $\mathrm{B}$ showed that tiotropium reversed the established goblet cell metaplasia. Thus, the mucus score as a measure of NE-induced goblet cell metaplasia was significantly lower in L-T20 than in L-N20 (L-N20 versus L-T20: $0.706 \pm 0.062$ versus $0.496 \pm 0.078 ; \mathrm{n}=12$ and $\mathrm{n}=10$, respectively; $\mathrm{p}<0.05$; fig. 6a). The total cell count and eosinophil count in BALF were significantly lower in L-T20 than in L-N20 (L-N20 versus L-T20: total cell count $28.8 \pm 6.20 \times 10^{4}$ versus $13.1 \pm 1.57 \times 10^{4}$ per $\mathrm{mL}$; $\mathrm{p}<0.05$, fig. $6 \mathrm{~b}$; eosinophil count $21.4 \pm 4.93 \times 10^{4}$ versus $6.57 \pm 1.49 \times 10^{4}$ per $\mathrm{mL} ; \mathrm{p}<0.05 ; \mathrm{n}=12$ and $\mathrm{n}=10$, respectively, fig. $6 \mathrm{~d}$ ). There were no significant differences between the two groups in macrophage count (fig. 6c) or counts of other cells on day 20 (data not shown).

\section{In vitro study}

MUC5AC production in NCl-H292 cells

Figure 7 shows the results of MUC5AC production in NCI-H292 cells. NE increased the MUC5AC level in the NCI-H292 cells in comparison with the control cells, and the percentage of MUC5AC level in NE-treated cells above the level in the control cells was $32.24 \pm 8.79 \%(p<0.05, n=10)$. Tiotropium inhibited NE-induced increase in MUC5AC level (tiotropium $10^{-6} \mathrm{M}$, $\left.3.66 \pm 9.66 \%, p=0.054 ; 10^{-5} \mathrm{M}, 0.44 \pm 4.11 \%, \mathrm{p}<0.05, \mathrm{n}=6\right)$, but tiotropium $\left(10^{-5} \mathrm{M}\right)$ per se had no effect on baseline MUC5AC
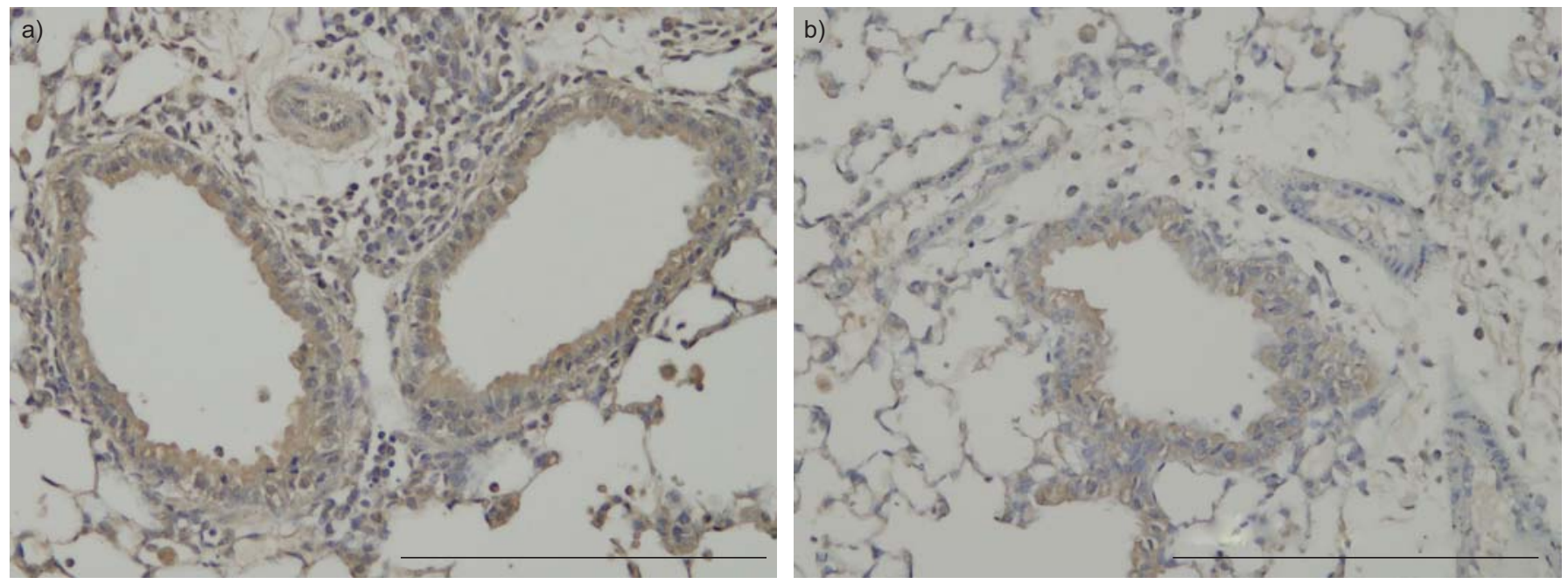

FIGURE 5. The lung sections immunohistochemically stained for $M_{3}$ receptors on day 11. a) Neutrophil elastase (NE) group, b) tiotropium group. Strong $M_{3}$ expression was especially observed in epithelial cells in the bronchi and inflammatory cells in the NE group. The $\mathrm{M}_{3}$ expression in the tiotropium group was less than that in the NE group. Scale bar $=200 \mu \mathrm{m}$. 

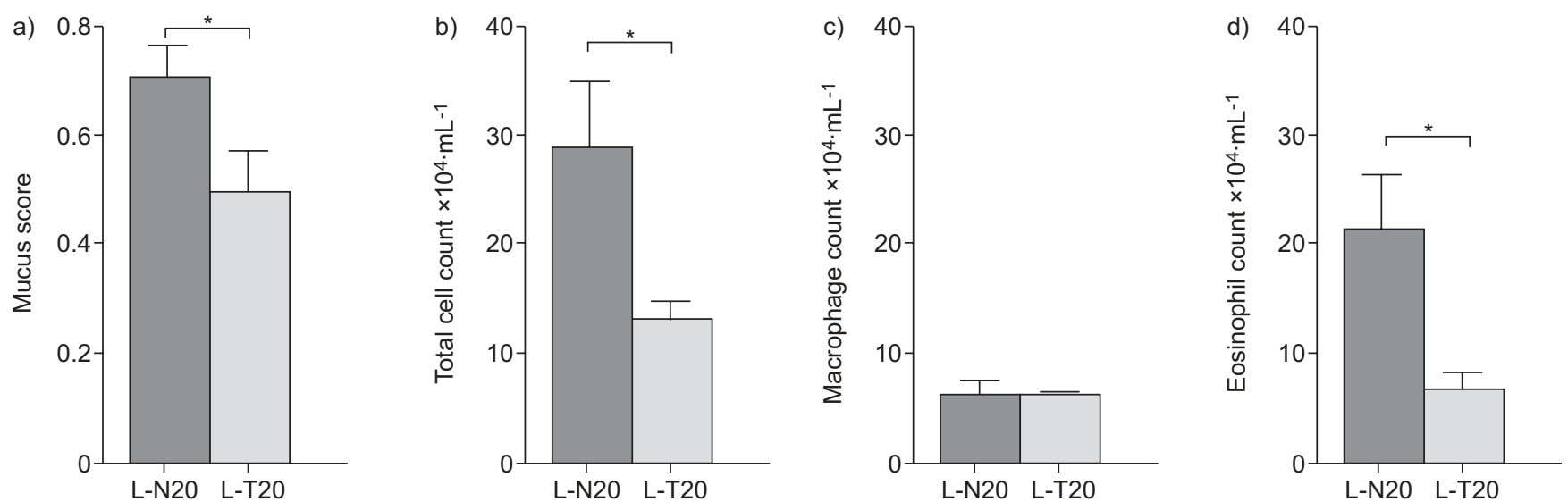

FIGURE 6. Therapeutic effect of late administration of tiotropium on established goblet cell metaplasia. a) Mucus score, b) total cell count, c) macrophage count, and d) eosinophil count. Comparison between the mucus scores and the results of bronchoalveolar lavage fluid cell analysis in the neutrophil elastase (NE) group ( $\square$ ) and tiotropium group ( $\square$ ). The NE group on day 20 and the tiotropium group on day 20 are referred to as L-N20 and L-T20, respectively. Tiotropium significantly reduced the mucus score, total cell count and eosinophil count on day 20. Data are presented as mean \pm SEM. NE group: $n=12 ;$ tiotropium group: $n=10$. ${ }^{*}: p<0.05$.

production $(-1.47 \pm 6.02 \%, \mathrm{n}=9)$. Ipratropium $\left(10^{-5} \mathrm{M}\right)$ inhibited NE-induced increase in MUC5AC level $(-7.89 \pm 1.73 \%, \mathrm{n}=4$, $\mathrm{p}<0.05)$. Carbachol $\left(10^{-6} \mathrm{M}\right)$ increased the MUC5AC level in NCI-H292 cells $(17.14 \pm 2.25 \%, \mathrm{n}=8, \mathrm{p}<0.05)$, and tiotropium $\left(10^{-5} \mathrm{M}\right)$ significantly inhibited the carbachol-induced increase in MUC5AC level $(1.24 \pm 6.55 \%, \mathrm{n}=7, \mathrm{p}<0.05)$.

\section{DISCUSSION}

In this study, we showed that repeated NE aspiration induced marked goblet cell metaplasia in mice in vivo and that its induction was inhibited by tiotropium. A therapeutic effect of

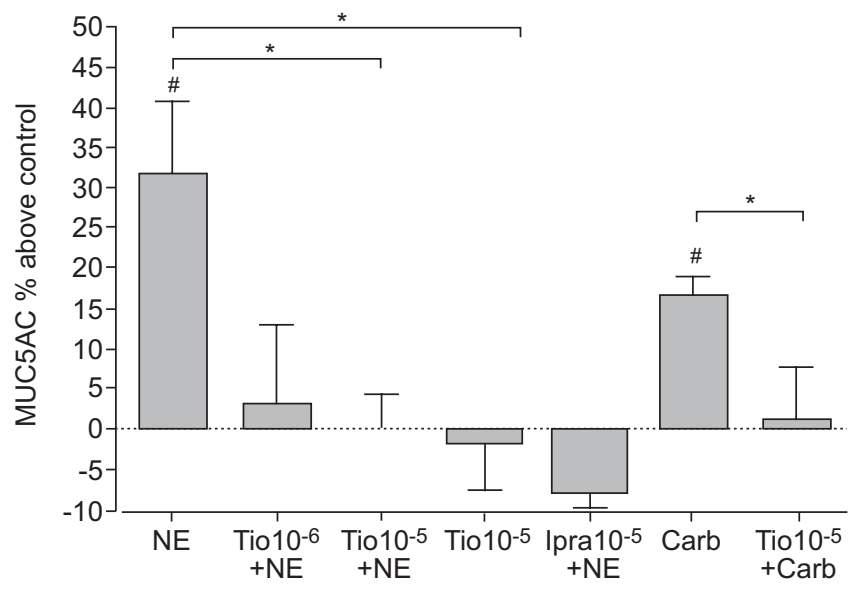

FIGURE 7. Effect of tiotropium (Tio) on neutrophil elastase (NE; $10^{-7} \mathrm{M}$ )induced MUC5AC production (cell lysate) in NCl-H292 cells. NE increased MUC5AC production in comparison with the control cells. Tiotropium inhibited NE-induced MUC5AC production and significance was obtained at $10^{-5} \mathrm{M}$, but tiotropium $\left(10^{-5} \mathrm{M}\right)$ per se had no effect on baseline MUC5AC production. Ipratropium (Ipra; $10^{-5} \mathrm{M}$ ) inhibited NE-induced increase in MUC5AC level. Carbachol (Carb; 10-6 M) increased the MUC5AC level in NCI-H292 cells, and tiotropium $\left(10^{-5} \mathrm{M}\right)$ inhibited the carbachol-induced increase in MUC5AC level. Data are presented as mean \pm SEM. $n=10$ for NE. $n=6$ for Tio $+N E ; n=9$ for Tio; $n=4$ for Ipra $+N E ; n=8$ for Carb; $n=7$ for Tio + Carb. ${ }^{\#}: p<0.05$; versus non-treated control cells. *: $p<0.05$. tiotropium was also observed on the established goblet cell metaplasia. The results also showed that tiotropium inhibited NE-induced MUC5AC production by NCI-H292 cells in vitro.

We modelled NE-induced goblet cell metaplasia in mice using a simple technique of intranasal instillation of NE on days 1, 4 and 7 under ether anaesthesia, and the metaplasia was similar to the metaplasia described by VoYNOw et al. [9], who induced it by allowing repeated aspiration of NE via the oropharyngeal route. Although the mechanism which leads to NE-induced goblet cell metaplasia is not fully elucidated, our data suggest that NE-induced inflammation may be associated with goblet cell metaplasia. Voynow et al. [9] reported that NE proteolytic activity is required for goblet cell metaplasia to occur because the NE inhibitor AAPV-CMK prevented NE-induced goblet cell metaplasia.

Our data using protocol $\mathrm{A}$ in figure 1 showed that NE aspiration, in triplicate, induced marked goblet cell metaplasia in N8 and N11 but spontaneously reverted in N14 and further in N20 (fig. 2c). Therefore, we confirmed that NE-induced goblet cell metaplasia spontaneously reverted at 7 days after last exposure of NE in our mouse model. Alternatively, our data using protocol B showed that NE aspiration, in six experiments, maintained marked goblet cell metaplasia in LN20 (fig. 6a). These data suggest that the continuous exposure to NE may be necessary to maintain marked goblet cell metaplasia.

The long-acting muscarinic receptor antagonist tiotropium is widely used as a bronchodilator for the treatment of COPD. In our study, tiotropium inhibited the development of NEinduced goblet cell metaplasia, suggesting that remodelling processes, such as NE-induced goblet cell metaplasia, are regulated by muscarinic receptors.

Our study also showed that tiotropium reduced the number of inflammatory cells in BALF (fig. 3a), suggesting that tiotropium may have anti-inflammatory action. Furthermore, the lung sections in the tiotropium group showed reduced $M_{3}$ receptor expression by immunohistochemistry especially in bronchial epithelial cells and inflammatory cells compared 
with those in the NE group (fig. 5), suggesting that antiinflammatory action of tiotropium may have suppressed the NE-induced $\mathrm{M}_{3}$ receptor expression in our model.

Muscarinic receptors have been known to be located on various cells, including epithelial cells and inflammatory cells. In COPD, macrophages express more $M_{3}$ receptors than $M_{1}$ or $M_{2}$ receptors and the numbers of $M_{1}$ and $M_{3}$ receptors on neutrophils tend to increase [15]. It was recently reported that tiotropium was found to inhibit the remodelling processes including airway smooth muscle hypertrophy, mucus gland hypertrophy and goblet cell hyperplasia, as well as inflammation in a guinea pig model of allergic asthma [16]. Although our model may differ from allergic models, a similar mechanism may be involved. Since it is well known that vagal tone is increased by airway inflammation in asthma and COPD, and recent evidence suggests that acetylcholine and its synthesising enzyme choline-acetyl transferase (ChAT) are ubiquitously expressed throughout the airways, including in epithelial cells and inflammatory cells, and acetylcholine synthesised by the ChAT is involved in the stimulation of post-junctional target cells by non-neuronal mechanism [7, 17], autocrine and paracrine stimulation of muscarinic receptors by acetylcholine secreted or produced through the inflammatory process may cause remodelling, including goblet cell metaplasia.

The results of our study also showed that the goblet cell metaplasia established in our COPD model was inhibited by late administration of tiotropium (protocol B). Tiotropium has been reported to prolong the time to the first exacerbation in a clinical study of COPD. Because excessive mucus secretion is the one of major symptoms in exacerbations of COPD, the therapeutic effect of tiotropium may be associated with inhibition of goblet cell metaplasia.

Our data showed that the increase of neutrophils in BALF on day 8 , and of eosinophils on day 11 was inhibited by tiotropium (figs $3 \mathrm{c}$ and $\mathrm{d}$ ) and that the increase in KC level in BALF was inhibited by tiotropium (fig. 4a). These findings suggest that tiotropium suppressed neutrophil accumulation by causing a decrease in KC. By contrast, IL-5 was detected on days 8, 11 and 14 , but the increases in IL-5 level were not inhibited by tiotropium. We also measured eotaxin, but difference in the levels between the two groups was not significant (data not shown). The levels of other eosinophilic chemoattractants, i.e., granulocyte macrophage colony-stimulating factor and RANTES, were reported to be below the level of detection in a previous study on NE-induced model of mice [9], suggesting that T-helper cell 2-type eosinophilic chemoattractants may not be associated with the inhibitory effect of tiotropium in this model.

Interestingly, our data showed that the $\mathrm{LTB}_{4}$ levels in BALF were increased in the NE-induced COPD model and that, on day 11 , the $\mathrm{LTB}_{4}$ level was lower in the tiotropium group than in the NE group (fig. 4c). Because $\mathrm{LTB}_{4}$ contributes to the recruitment and activation of leukocytes, including both eosinophils and neutrophils, via BLT1 [18], the increase in eosinophils in BALF on day 11 may have been mediated by $\mathrm{LTB}_{4}$. Recent evidence suggests that muscarinic receptors are involved in airway inflammation in COPD patients through acetylcholine-induced, ERK1/2-dependent $\mathrm{LTB}_{4}$ release from sputum cells and monocytes [15]. Since Buhling et al. [19] found that most neutrophil chemotactic activity released from macrophages, monocytes and epithelial cells, in response to $\mathrm{ACh}$, could be attributed to $\mathrm{LTB}_{4}$, tiotropium may interrupt the vicious cycle of inflammation induced by $\mathrm{LTB}_{4}$ production via muscarinic receptors in COPD.

Our in vitro study demonstrated that tiotropium inhibited NEstimulated MUC5AC production (fig. 7), suggesting a direct effect of tiotropium on NE-induced mucin production in airway epithelial cells. NE has been found to act on the epithelial cell surface [20] and activate signalling via multiple pathways, including generation of reactive oxygen species [21, 22], activation of toll-like receptor 4 [23] and activation of the epidermal growth factor receptor (EGFR) [11]. Transforming growth factor- $\alpha$, cleaved by NE, and reactive oxygen species, produced by NE, have been shown to activate EGFR and induce MUC5AC production in NCI-H292 cells in vitro [11]. Our study showed that tiotropium inhibited carbachol-induced increase in MUC5AC production and that another muscarinic receptor antagonist ipratropium inhibited NE-induced increase in MUC5AC, suggesting that effects of NE on mucin production are explained by activation of muscarinic receptors in NCI-H292 cells. As a classical study demonstrated that NE affects muscarinic-receptormediated events in airway smooth muscles [24], the interaction between $\mathrm{NE}$ and muscarinic receptors may be involved in mucin production by NCI-H292 cells. Although it may be difficult to apply the results of in vitro experiments using human cell line into in vivo study of mice, we speculate that tiotropium may have inhibited goblet cell metaplasia by inhibiting NE-induced MUC5AC protein production via direct action on epithelial cells in our model. However, further studies are needed to demonstrate the effect of tiotropium on NE-induced goblet cell meaplasia or MUC5AC production by using primary epithelial cells in mice.

Our studies demonstrated that tiotropium inhibits NE-induced goblet cell metaplasia in vivo and mucin production in vitro, probably mediated by suppression of inflammation and by a direct effect on epithelial cells. Since mucus overproduction is associated with a poor prognosis of COPD, tiotropium may be an effective drug for treating mucus overproduction in COPD.

\section{STATEMENT OF INTEREST}

None declared.

\section{ACKNOWLEDGEMENTS}

The authors thank M. Shino and Y. Sugimura (First Department of Medicine, Tokyo Women's Medical University School of Medicine, Tokyo, Japan) for their technical assistance.

\section{REFERENCES}

1 Hogg JC, Chu F, Utokaparch S, et al. The nature of small-airway obstruction in chronic obstructive pulmonary disease. $N$ Engl J Med 2004; 350: 2645-2653.

2 Hogg JC, Chu FS, Tan WC, et al. Survival after lung volume reduction in chronic obstructive pulmonary disease: insights from small airway pathology. Am J Respir Crit Care Med 2007; 176: 454-459.

3 Nadel JA, Takeyama K, Agusti C. Role of neutrophil elastase in hypersecretion in asthma. Eur Respir J 1999; 13: 190-196. 
4 Breuer R, Lucey EC, Stone PJ, et al. Proteolytic activity of human neutrophil elastase and porcine pancreatic trypsin causes bronchial secretory cell metaplasia in hamsters. Exp Lung Res 1985; 9: 167-175.

5 Vincken W, van Noord JA, Greefhorst AP, et al. Improved health outcomes in patients with COPD during $1 \mathrm{yr}^{\prime}$ s treatment with tiotropium. Eur Respir J 2002; 19: 209-216.

6 Tashkin DP, Celli B, Senn S, et al. A 4-year trial of tiotropium in chronic obstructive pulmonary disease. N Engl J Med 2008; 359: 1543-1554.

7 Racke K, Matthiesen S. The airway cholinergic system: physiology and pharmacology. Pulm Pharmacol Ther 2004; 17: 181-198.

8 Kai H, Yoshitake K, Hisatsune A, et al. Dexamethasone suppresses mucus production and MUC-2 and MUC-5AC gene expression by NCI-H292 cells. Am J Physiol 1996; 271: L484-L488.

9 Voynow JA, Fischer BM, Malarkey DE, et al. Neutrophil elastase induces mucus cell metaplasia in mouse lung. Am J Physiol Lung Cell Mol Physiol 2004; 287: L1293-L1302.

10 Nagai A, Inano H, Takizawa T. Morphologic changes in the airways induced by recurrent exposure of acetylcholine in the guinea pig. Am Rev Respir Dis 1990; 142: 172-176.

11 Kohri K, Ueki IF, Nadel JA. Neutrophil elastase induces mucin production by ligand-dependent epidermal growth factor receptor activation. Am J Physiol Lung Cell Mol Physiol 2002; 283: L531-L540.

12 Takeyama K, Dabbagh K, Lee HM, et al. Epidermal growth factor system regulates mucin production in airways. Proc Natl Acad Sci USA 1999; 96: 3081-3086.

13 Burgel PR, Lazarus SC, Tam DC, et al. Human eosinophils induce mucin production in airway epithelial cells via epidermal growth factor receptor activation. J Immunol 2001; 167: 5948-5954.

14 Phillips JE, Case NR, Celly C, et al. An enzyme-linked immunosorbent assay (ELISA) for the determination of mucin levels in bronchoalveolar lavage fluid. J Pharmacol Toxicol Methods 2006; 53 160-167.

15 Profita M, Giorgi RD, Sala A, et al. Muscarinic receptors, leukotriene B4 production and neutrophilic inflammation in COPD patients. Allergy 2005; 60: 1361-1369.

16 Gosens R, Bos IS, Zaagsma J, et al. Protective effects of tiotropium bromide in the progression of airway smooth muscle remodeling. Am I Respir Crit Care Med 2005; 171: 1096-1102.

17 Wessler IK, Kirkpatrick CJ. The non-neuronal cholinergic system an emerging drug target in the airways. Pulm Pharmacol Ther 2001, 14: 423-434

18 Medoff BD, Tager AM, Jackobek R, et al. Antibody-antigen interaction in the airway drives early granulocyte recruitment through BLT1. Am J Physiol Lung Cell Mol Physiol 2006; 290: L170-L178.

19 Buhling F, Lieder N, Kuhlmann UC, et al. Tiotropium suppresses acetylcholine-induced release of chemotactic mediators in vitro. Respir Med 2007; 101: 2386-2394.

20 Christensen TG, Alonso PA. Immunocytochemical evidence for extra-cellular initiation of elastase-induced bronchial secretory cell metaplasia in hamsters. Eur Respir J 1996; 9: 535-541.

21 Aoshiba K, Yasuda K, Yasui S, et al. Serine proteases increase oxidative stress in lung cells. Am J Physiol Lung Cell Mol Physiol 2001; 281: L556-L564.

22 Fischer BM, Voynow JA. Neutrophil elastase induces MUC5AC gene expression in airway epithelium via a pathway involving reactive oxygen species. Am J Respir Cell Mol Biol 2002; 26: 447-452.

23 Devaney JM, Greene CM, Taggart CC, et al. Neutrophil elastase up-regulates interleukin-8 via toll-like receptor 4. FEBS Lett 2003; 544: 129-132.

24 Christensen GC, Lev A, Ryan J, et al. Rabbit trachealis tension responses to receptor-mediated agonists are diminished by elastase. Am J Respir Cell Mol Biol 1992; 6: 498-503. 